\title{
NILAI BUDAYA PADA SISTEM USAHATANI POLA 'DUSUN' SUKU KANUM DI KAMPUNG YANGGANDUR KABUPATEN MERAUKE
}

\author{
The Cultural Values on 'Dusun' Pattern Farming System of \\ The "Kanum" Tribe in Yanggandur Village Merauke Regency \\ Puji Susanty*, Yunus Musa, Rahmadanih, Sitti Bulkis \\ *Politeknik Pertanian Yasanto, Merauke \\ (email: pujisusanti74@gmail.com)
}

\begin{abstract}
"Dusun" is a specific area of the traditional land in Kanum Tribe, which been chosen as place for farmer to cultivated as rural areas for families or in Kanum Tribes Group Society that been inherite from generation to generation. This research aimed to describe the cultural values in managing the farming system of "dusun" pattern carried out by indigenous community of Kanum Tribe. The research was conducted in Yanggandur Village, Merauke Regency. Qualitative approach and snowball sampling method were applied to collect the data through interviews from informants. In order to analyze the data it applied data reduction techniques, presentation and conclusion as well as verification. From the research, it was indicated that the prime food crop that cultivated by Kanum Tribe in the "dusun" are 'kumbili'. The Kanum Tribe still active managed the farming system of "dusun" pattern because the "kumbili" farming system contained the cultural values which they had inherited from generation to generation. The cultural values contained in "kumbili" cultivation were the safety and religious value, the wisdom and mutual cooperation value, and the responsibility value.
\end{abstract}

Kyewords: cultural value, "dusun" pattern farming, Kanum tribe.

\begin{abstract}
Abstrak
Dusun adalah suatu luasan areal lahan yang terpilih sebagai tempat melakukan kegiatan usaha pertanian dalam keluarga atau kelompok marga pada masyarakat adat Suku Kanum di Kabupaten Merauke yang telah diwariskan dari generasi ke generasi. Tujuan penelitian ini adalah mendeskripsikan nilai budaya pada sistem usaha tani pola dusun yang dilakukan oleh masyarakat asli Suku Kanum yang bermukim di Kampung Yanggandur Kabupaten Merauke. Penelitian ini menggunakan metode kualitatif dengan teknik snowball sampling. Penggalian data dilakukan melalui wawancara dari satu informan ke informan lainnya. Teknik analisis data dilakukan melalui tahap pereduksian data, penyajian data, dan penarikan kesimpulan, serta pemverifikasian. Hasil penelitian menunjukkan bahwa tanaman pangan utama yang diusahakan oleh Suku Kanum adalah Kumbili. Komunitas Suku Kanum di Kampung Yanggandur masih aktif mengelola sistem usaha tani pola dusun karena kegiatan budi daya tanaman kumbili mengandung nilai budaya yang telah diwariskan secara turun-temurun. Adapun nilai budaya yang terkandung di dalamnya adalah nilai keselamatan dan religi, nilai kebersamaan dan nilai kegotongroyongan serta nilai tanggunjawab.
\end{abstract}

Kata kunci : nilai budaya, usahatani pola "dusun"; Suku Kanum 
Sitasi: Puji Susanty, Yunus Musa, Rahmadanih, Sitti Bulkis, 2019. Nilai Budaya Pada Sistem Usahatani Pola 'Dusun' Suku Kanum Di Kampung Yanggandur Kabupaten Merauke, JSEP 15(2): 144 - 155.

\section{Pendahuluan}

Indonesia merupakan negara agraris yang sebagian besar penduduknya adalah petani. Sebagai negara yang sedang berkembang, sistem pertanian Indonesia berkembang pesat dari sistem pertanian tradisional organik menjadi sistem pertanian sawah modern menggunakan pupuk sintetis dan pestisida kimiawi (Yunus et.al, 2016) atau bahkan sudah tercemari oleh dampak pertambangan (Meisanti et.al, 2012). Namun demikian masih banyak wilayah di Indonesia yang petaninya melakukan sistem pertanian tradisional yang ditujukan untuk memenuhi kebutuhan hidup petani secara subisten, dimana sistem ini mampu bertahan selama berabad-abad memenuhi kebutuhan pangan masyarakat (Lanalefo, et.al, 2013). Hal ini berlangsung karena sistem pertanian tradisional sangat berhubungan dengan nilai budaya yang mampu menjaga kehidupan sosial masyarakat dalam komunitas dan mampu menjaga keseimbangan lingkungan, namun tidak berorientasi ekonomi komersial.

Nilai budaya dalam kehidupan Suku Kanum sangat beragam terutama yang berhubungan dengan kegiatan pertanian. Suku Kanum merupakan penduduk asli yang tinggal di Kabupaten Merauke secara turun temurun. Komunitas Suku Kanum yang berdiam di Kampung Yanggandur merupakan bagian dari penduduk asli pemilik wilayah ulayat yang termasuk dalam wilayah konservasi Balai Taman Nasional Wasur yang dideklarasikan tanggal 23 Mei 1997 berdasarkan keputusan Menteri Kehutanan No. 282/Kpts-VI/1997 dengan luas keseluruhan 413.810 Ha (BTNW 1999).

Tempat untuk mengumpulkan bahan makanan dan kebutuhan lainnya disebut 'dusun' oleh masyarakat Suku Kanum dan memiliki ikatan yang sangat kuat dengan tanah adat leluhurnya. Kondisi ini sama dengan masyarakat Negeri Saleman Utara di Maluku dimana pembentukan kebun atau dusun oleh masyarakat umumnya untuk kepentingan sosial budaya dan nilai ekonomi rumah tangga. Nilai sosial budaya dari kebun adalah keterkaitan antara budaya bercocok tanam secara campuran dalam suatu bidang lahan (Purwanto dan Ariane, 2010).

"Dusun" adalah suatu luasan areal lahan yang terpilih sebagai tempat melakukan kegiatan usaha pertanian dalam keluarga atau kelompok marga pada masyarakat adat Suku Kanum di Kabupaten Merauke yang telah diwariskan dari generasi ke generasi. Kegiatan pertanian yang dilakukan khususnya untuk pemenuhan kebutuhan konsumtif pangan keluarga, bahan dan ramuan tanaman yang dibutuhkan dalam penyelenggaraan ritualisasi budaya, dan tanaman obatobatan tradisional.

Adanya pengaruh budaya luar yang masuk dan arus modernisasi menyebabkan perubahan pola hidup masyarakat lokal. Hampir semua suku di Papua mengalami perubahan kebiasaan pangan pokok yang semula sagu atau umbiumbian beralih ke beras. Walaupun banyak pengaruh luar yang datang namun demikian Suku Kanum masih tetap memelihara nilai tradisi sistem pertanian pola dusun sebagai sumber pangan rumah tangga. Komunitas lain yang memiliki nilai- 
budaya sangat nyata terlihat pada Suku Arfak di Papua Barat, nilai-nilai tentang pentingnya menjaga kelestarian lingkungan hidup termanifestasikan dalam bentuk masyarakat etnis Arfak hidup mencari nafkah dengan berkebun (Mulyadi dan Iyai, 2016). Nilai-nilai sosial budaya Pokadulu pada masyarakat Desa Warambe diantaranya nilai kebersamaan, persatuan, tolong menolong dan sosialisai diterapkan dalam kegiatan pertanian mulai pada saat pembukaan dan pembersihan lahan, bercocok tanam hingga panen maupun aktivitas sosial lannya yang masih diterapkan hingga sekarang di Kabupaten Muna (Darwin et.al., 2016).

Peningkatan kebutuhan ekonomi dan nilai uang sebagai alat tukar dengan barang konsumtif dari luar sudah banyak menggeser perilaku dan pola pikir sebagian besar komunitas Sub Suku Marind lainnya, namun Suku Kanum masih tetap mempertahankan tradisi sistem pertanian pola "dusun". Kemandirian pangan Suku Kanum pada skala mikro yaitu dengan memanfaatkan pangan lokal kumbili dan sagu untuk memenuhi kebutuhan pangan. Tujuan dari penelitian ini adalah mendeskripsikan secara analitik nilai budaya pada pengelolaan sistem usahatani pola "dusun" yang dilakukan oleh Suku Kanum dalam memenuhi kebutuhan pangan.

\section{Metode Penelitian}

Penelitian ini menggunakan pendekatan kualitatif untuk menghasilkan informasi yang menyeluruh dan jelas tentang nilai budaya yang terkandung dalam pengelolaan sistem usahatani pola "dusun" pada masyarakat asli Suku Kanum. Lokasi penelitian adalah Kampung Yanggandur Kabupaten Merauke, dengan pertimbangan bahwa jumlah masyarakat asli Suku Kanum yang tinggal di kampung ini masih cukup banyak yaitu 102 KK (pendatang $10 \mathrm{KK}$ ) terdiri dari 486 jiwa (BPS, 2017) dan kegiatan pengelolaan sistem usahatani pola dusun masih aktif dilakukan walaupun ada beberapa "dusun" yang kurang terpelihara. Penentuan informan dilakukan dengan teknik snowball sampling. Total informan yang telah diwawancarai secara mendalam (depth interview) ada delapan orang.

Selain depth interview, pengumpulan data dilakukan pula dengan teknik observasi dan pengumpuan dokumen. Data yang dikumpulkan meliputi profil Suku Kanum, jenis tanaman pangan dalam "dusun", dan bentuk nilai budaya yang terkandung dalam sistem pengelolaan usahatani pola "dusun" secara adat/tradisional. Analisis data dilakukan secara deskriptif kualitatif, sejak sebelum memasuki lapangan, selama di lapangan, dan setelah selesai di lapangan. Analisis data sebelum peneliti memasuki lapangan adalah analisis terhadap data hasil studi pendahuluan dan data sekunder, yang akan digunakan untuk menentukan fokus penelitian. Pada saat wawancara, peneliti sudah melakukan analisis terhadap jawaban yang diwawancarai, setelah dianalisis terasa belum memuaskan maka peneliti melanjutkan pertanyaan lagi, sampai tahap tertentu, diperoleh data yang dianggap kredibel (Sugiyono, 2015).

Langkah-langkah analisis data meliputi koleksi data, peneliti mengumpulkan data dari data hasil penelusuran dokumen, pengamatan di lapangan dan hasil wawancara. Setelah itu reduksi data, merupakan suatu bentuk analisis yang menajamkan, menggolongkan, mengarahkan, membuang yang tidak perlu dan mengorganisasi data sedemikian rupa sehinga kesimpulan-kesimpulan finalnya dapat ditarik dan diverifikasi (Silalahi, 2009). Selanjutnya penyajian data, yaitu 
sebagai sekumpulan informasi tersusun yang memberi kemungkinan adanya penarikan kesimpulan dan pengambilan tindakan. Penarikan kesimpulan dan verifikasi kesimpulan merupakan temuan baru yang sebelumnya belum pernah ada. Temuan dapat berupa deskripsi atau gambaran suatu obyek yang sebelumnya masih remang-remang atau gelap sehingga setelah diteliti menjadi jelas, dapat berupa hubungan kausal atau interaktif, hipotesis atau teori (Sugiyono, 2016).

\section{Hasil dan Pembahasan}

\section{Profil Masyarakat Suku Kanun}

Masyarakat Suku Kanum merupakan suku asli yang secara turun temurun telah mendiami daerah Kampung Yanggandur dan sekitarnya sebagai pemilik hak ulayat (Hak Tanah Adat) dengan luas $375,88 \mathrm{Km}^{2}$ dan jumlah penduduk sebanyak 486 jiwa yang terdiri dari 251 laki-laki dan 235 perempuan, $112 \mathrm{KK}$ yang terdiri dari 102 KK Kanum, 10 KK pendatang (Monografi Kampung, 2018). Pendatang yang tinggal di Kampung Yanggandur sebagian besar adalah tenaga guru SMP dan SD yang menetap di kampung dan satu KK pendatang dari Pulau Jawa sebagai pedagang.

Pola peramu dan kepemilikan dusun sampai saat ini masih dilakukan masyarakat Kampung Yanggandur sebagai satu-satunya sumber pemenuhan kebutuhan hidup dan pendapatan keluarga. Kegiatan usaha pemanfaatan sumber daya alam yang dilakukan oleh masyarakat secara tradisional (meramu) antara lain (1) berburu binatang yang laku dijual (babi hutan, rusa, kasuari dan kangguru), (2) menangkap ikan di rawa-rawa terutama pada musim kemarau, dan (3) kegiatan menyuling minyak kayu putih serta (4) mengumpulkan kemiri untuk dijual. Umumnya kegiatan pemanfaatan sumber daya alam ini dilakukan untuk mendapatkan penghasilan bagi pemenuhan kebutuhan keluarga sehari-hari. Sedangkan untuk pemenuhan kebutuhan makanan pokok masih dilakukan dengan mengelola dusun kumbili dan sagu sebagai lahan pertanian tradisional. Pengelolaan lahan tradisional ini juga dilakukan dengan menanam tanaman lain seperti pisang, umbi-umbian sebagai tambahan makanan pokok dan tanaman buah-buahan seperti mangga, nenas, jeruk, sukun, nangka, kedondong dan tanaman lain yang bibitnya diperoleh dari luar.

\section{Sistem Usahatni Pola "Dusun"}

"Dusun" merupakan tempat melakukan kegiatan usaha pertanian dalam keluarga atau kelompok marga pada masyarakat adat Suku Kanum di Kabupaten Merauke yang telah diwariskan dari generasi ke generasi. Luasan dusun bervariasi bagi masing-masing marga, terdapat enam marga Suku Kanum yaitu Mbanggu, Ndimar, Ndiken, Gelambu, Maywa dan Saggra.

Penetapan suatu wilayah sebagai tempat untuk melaksanakan kegiatan pertanian selalu mempunyai ciri khas khusus yaitu ada sumber air berupa genangan air dengan diameter antara 4 - 10 meter dan kedalaman antara 1- 5 meter tergantung musim. Sumber air ini mereka sebut sumur alam.

Jenis tanaman pangan utama yang diusahakan adalah kumbili. Pangan ini adalah makanan pokok Suku Kanum secara turun temurun, sehingga budidaya 
tanaman kumbili sudah menyatu dengan kehidupan masyarakat. Kumbili memiliki nilai budaya yang tinggi yaitu sebagai bahan utama pada acara adat dan mas kawin pada acara pernikahan. Oleh karenanya membudidayakan kumbili merupakan keharusan bagi Suku Kanum.

Masyarakat Suku Kanum membedakan kumbili menjadi dua yaitu kumbili jantan dan kumbili betina berdasarkan bentuk dan banyaknya umbi. Kumbili disebut jantan apabila umbinya bulat dan lebar, satu tanaman hanya menghasilkan $6-10$ umbi, dimana terdapat 3-4 umbi besar dan lainnya berukuran sedang atau kecil. Sedangkan kumbili betina biasanya bentuk umbi lonjong satu tanaman menghasilkan 13 - 16 umbi dengan ukuran sedang dan kecil, namun terkadang ada juga 1 - 2 umbi yang berukuran besar seperti kumbili jantan.

Secara umum budidaya kumbili yang dilakukan oleh masyarakat Kanum menggunakan sistem ladang berpindah, setiap musim tanam menggunakan lahan baru. Persiapan lahan dilakukan pada bulan September yaitu dengan melakukan pembersihan dan membuat kuming yaitu bumbunan tanah bercampur sisa tanaman atau rumput sebagai tempat penanaman umbi. Penanaman menggunakan umbi yang telah bertunas pada bulan Oktober.

Kegiatan pemeliharaan berupa memasang tajar pendek pada saat tanaman berumur dua minggu, dan bila batang kumbili telah dililit pada tajar pendek sebanyak 3-4 lilitan maka pasang tajar kedua dengan tinggi 3-5 meter untuk tempat menjalarnya tanaman selanjutnya. Panen kumbili pada bulan Juli atau Agustus ketika daun tanaman kumbili sudah berwarna kuning atau mengering. Umbi kumbili yang telah dipanen kemudian disimpan dalam gudang (keter menk) yang ada dekat lahan tempat tanam kumbili.

Penyimpanan dalam gudang untuk mencegah dari sinar matahari sehingga umbi awet. Persediaan kumbili di gudang ini biasanya dapat memenuhi kebutuhan konsumsi keluarga 5 - 6 bulan ke depan. Apabila disimpan lebih dari 6 bulan maka rasa kumbili sudah kurang enak. Umbi kumbili untuk konsumsi dengan cara dikukus, dibakar dan dibuat sep.

Tanaman pangan sebagai makanan pokok selain kumbili adalah sagu, keladi, ubi kayu dan pisang yang selalu tersedia di dusun dan ada beberapa keluarga yang menanamnya di lahan pekarangan rumah. Sedangkan tanaman penting lainnya yang juga ditanam adalah tanaman wati (Piper methysticum), tebu (Saccharum oficinarum) pinang hutan (Arenga sp.) dan kelapa (Cocos nucifera L.) merupakan tanaman untuk acara ritual adat.

Setiap ritual adat (doa bersama) saat pembukaan lahan dan penanaman serta panen masih aktif dilakukan karena adanya kepercayaan yang kuat bahwa Dewa yang mengatur pertumbuhan dan perkembangan tanaman kumbili. Pemimpin doa atau yang membacakan mantera umumnya dibacakan kepala keluarga yang telah diajarkan secara lisan oleh orangtuanya, walaupun tanaman kumbili merupakan totem (pemujaan/kepercayaan pada tumbuhan dan hewan) dari marga Sanggra namun marga lain juga mengetahuinya. Berdasarkan hasil depth interview informan tidak bersedia memberitahukan ucapan doanya karena dianggap "pamali" sehingga hanya memberitahukan makna/manfaatnya saja.

Dalam setiap ritual adat selalu diakhiri dengan makan bersama, hal ini menunjukkan hubungan sosial diantara masyarakat Suku Kanum masih terpelihara. Menurut informan AG untuk menjaga hubungan persaudaraan antar keluarga maka 
harus saling peduli, hadir saat diundang untuk merayakan kebahagiaan dan menolong saat ada keluarga yang sedang kesusahan atau membantu meringankan pekerjaan keluarga lain.

Nilai kebersamaan ini juga terlihat saat kegiatan mengunjungi dusun untuk melakukan kegiatan pengelolaan sistem usahatani yaitu bapak, ibu dan seluruh anak-anak serta seluruh anggota yang tinggal dalam rumah terlibat bekerja di kebun. Pada kesempatan inilah orangtua mengajarkan kepada anak-anak segala hal tentang ritual adat, menunjukkan batas-batas wilayah, menyampaikan nasehat dan ceritacerita tentang leluhur mereka. Kunjungan ke dusun jaman dahulu sekitar 1-2 minggu keluarga tinggal dan menginap, namun saat ini kunjungan ke dusun dalam waktu lama hanya dilakukan saat liburan anak-anak sekolah, selain itu hanya dilakukan untuk mengambil hasil dan membersihkan kebun sekedarnya saja sehingga bisa dilakukan dalam sehari pulang pergi. Keadaan ini mulai terjadi sejak Pemerintah mengharuskan anak-anak bersekolah sekitar tahun 1990, sehingga frekwensi kunjungan ke dusun mulai berkurang.

\section{Nilai Budaya pada Pengelolaan Sistem Usahatani Pola Dusun}

Nilai-nilai budaya adalah nilai-nilai yang disepakati oleh semua anggota masyarakat, suku atau bangsa. Sedangkan yang dimaksud dengan "Sistem Nilai Budaya" pada dasarnya adalah urutan dari semua nilai yang dipegang oleh sebuah kelompok atau suku berdasarkan derajat penting nilai-nilai tersebut (Saputra, 2011). Sistem Nilai budaya suatu suku akan berbeda dengan suku lain walaupun bisa ada satu atau dua nilai yang derajatnya tidak sama. Perbedaan itu disebabkan oleh sejumlah faktor antara lain sejarah bangsa dan negara masing-masing, kondisi geografis, sistem politik, agama yang dominan dan tingkat pendidikan warganya (Ruky, 2017). Nilai budaya pada sistem usahatani pola "dusun" mencakup nilai budaya yang terkait dengan rangkaian kegiatan mulai persiapan lahan garapan sampai pada pemanenan.

\section{Persiapan Lahan Garapan.}

Kegiatan persiapan lahan untuk memulai kegiatan budidaya tanaman kumbili dan jenis umbi-umbian lain di dusun dilakukan saat akhir musim kemarau yaitu pada bulan Agustus atau September. Beberapa kegiatan yang dilakukan adalah penentuan lahan, pembersihan lahan, pemagaran dan pembagian petak lahan.

Proses penentuan (survei) lahan dilakukan bersama-sama oleh anggota keluarga yang tinggal dalam rumah dan keluarga lain yang akan membantu membuka lahan. Bila lahan telah disetujui bersama maka ditanam patok pada empat sudut luasan lahan yang akan digarap. Setelah itu persiapan melakukan ritual adat (doa bersama) dengan cara membuat sep (batu dan kayu dibakar kemudian letakkan bahan makanan diatasnya).

Nilai budaya yang terkandung dalam kegiatan pembukaan lahan yaitu Nilai Keselamatan dan Religi. Dalam hal ini, masyarakat Suku Kanum mempercayai bahwa kehidupan mereka ada yang mengendalikan secara spiritual walaupun pada kenyataannya sebagian besar masyarakat Suku Kanum di Kampung Yanggandur beragama Katolik. Mereka percaya bahwa semua lahan yang akan dikelola adalah 
milik Dema sehingga masyarakat Suku Kanum harus melakukan ritual pembuatan sep sebelum membuka lahan garapan. Kegiatan ritual ini cenderung sama dengan kegiatan yang dilakaukan oleh Komunitas Bunggu di Kabupaten Mamuju Utara (Ali dan Rahmadanih, 2017). Dalam ritual tersebut masyarakat memohon ijin kepada Dema akan menggunakan lahan untuk menanam kumbili, selanjutnya memohon doa kiranya Dema mau memberikan perlidungan bagi keluarga dan kerabat yang membantu dalam mengusahakan tanaman adat. Selain mengandung nilai keselamatan dan religi, terkandung pula nilai kebersamaan (Tabel 1).

\section{Tabel 1.}

\section{Nilai Budaya yang berkaitan dengan Persiapan Lahan Garapan}

\begin{tabular}{|c|c|c|c|}
\hline No & Jenis Kegiatan & Nilai Budaya & Makna/Manfaat \\
\hline \multirow[t]{3}{*}{1} & \multirow[t]{3}{*}{$\begin{array}{l}\text { Ritual adat pada } \\
\text { proses penentuan } \\
\text { lahan }\end{array}$} & Religi & $\begin{array}{l}\text { Permohonan izin kepada Dema } \\
\text { (mereka percaya bahwa semua lahan } \\
\text { yang akan dikelola ada pemilik atau } \\
\text { penjaganya) }\end{array}$ \\
\hline & & Keselamatan & $\begin{array}{l}\text { Berdoa untuk keselamatan bersama } \\
\text { (mereka percaya bahwa kehidupan } \\
\text { mereka ada yang mengendalikan } \\
\text { secara spiritual sehingga dengan } \\
\text { berdoa bersama mereka percaya akan } \\
\text { diberikan keselamatan dalam } \\
\text { mengelola lahan) }\end{array}$ \\
\hline & & Kebersamaan & $\begin{array}{l}\text { Persatuan/kekerabatan antar sesama } \\
\text { warga / suku (mereka percaya bahwa } \\
\text { semua jenis pekerjaan dan harapan } \\
\text { lebih mudah membuahkan hasil bila } \\
\text { dilakukan secara bersama-sama) }\end{array}$ \\
\hline \multirow[t]{2}{*}{2} & \multirow[t]{2}{*}{$\begin{array}{l}\text { Pembersihan } \\
\text { lahan }\end{array}$} & Religi & $\begin{array}{l}\text { Kepercayaan bahwa Dema akan selalu } \\
\text { mendampingi mereka dalam } \\
\text { melakukan pekerjaan. }\end{array}$ \\
\hline & & Kebersamaan & $\begin{array}{l}\text { Persatuan kekerabatan antar sesama } \\
\text { warga/ suku diwujudkan dalam } \\
\text { bentuk saling membantu melakukan } \\
\text { pekerjaan ini. }\end{array}$ \\
\hline \multirow[t]{2}{*}{3} & \multirow[t]{2}{*}{$\begin{array}{l}\text { Pembagian petak } \\
\text { lahan }\end{array}$} & Tanggungjawab & $\begin{array}{l}\text { Melibatkan dan mengajarkan anak- } \\
\text { anak sedari kecil untuk melakukan } \\
\text { budidaya kumbili dan jenis tanaman } \\
\text { lain (mereka percaya dengan } \\
\text { pembagian petak lahan yang sedini } \\
\text { mungkin maka semakin memicu } \\
\text { munculnya rasa tanggungjawab } \\
\text { masyarakat Suku Kanum dalam } \\
\text { mengelola kegiatan usahatani pola } \\
\text { dusun yang merupakan haknya) }\end{array}$ \\
\hline & & Kebersamaan & $\begin{array}{l}\text { Anggota rumah tangga kompak } \\
\text { melakukan kegiatan budidaya di satu } \\
\text { 'dusun' secara bersama-sama }\end{array}$ \\
\hline
\end{tabular}

Sumber : Data primer 2018 
Pembagian petak lahan (luasan lahan) yang ada dibagi menurut jumlah anggota keluarga yang tinggal dalam rumah. Umumnya masing-masing anggota keluarga mendapat bagian tanah dengan ukuran lebar 5 - 10 meter dan panjang 100 meter. Pembagian mulai dari pinggir yaitu untuk bapak, saudara laki-laki, anak lakilaki, ibu, saudari perempuan dan anak perempuan yang tinggal dalam rumah dan dianggap sudah mampu. Makna dari melibatkan seluruh anggota rumahtangga dalam kegiatan budidaya adalah sebagai bentuk tanggung jawab dan mengajarkan anak sejak dini tentang cara mengelola dusun.

\section{Nilai Budaya Terkait dengan Penanaman.}

Kegiatan ini diawali dengan persiapan benih. Pada saat kegiatan pembersihan lahan, keluarga sudah menyiapkan benih/bibit yang akan ditanam di "dusun". Khusus untuk tanaman kumbili, umbi yang disimpan dalam gudang (keter menk) telah disisihkan khusus untuk benih. Jika umbi yang disimpan dalam gudang sudah mulai bertunas pada bulan September, merupakan tanda bagi masyarakat Suku Kanum untuk mulai melakukan pembersihan lahan.. Ketika melakukan kunjungan ke dusun sambil melakukan kegiatan pembersihan lahan, mereka mempersiapkan benih dan melibatkan anak-anak sehingga anak-anak sedari kecil sudah diajarkan mengenai cara persiapan benih termasuk memilih tanaman yang cocok untuk bibit yaitu dengan melihat fisik tanaman.

Kegiatan penanaman selalu dilakukan pada bulan Oktober baik saat musim hujan maupun kemarau. Sebelum kegiatan penanaman, masyarakat Suku Kanum menyiapkan ritual adat untuk doa bersama. Kepala keluarga kembali menancapkan kayu misar di tengah-tengah kebun kemudian dilakukan persiapan sama dengan ketika kegiatan ritual saat pembukaan lahan. Kegiatan doa bersama dilakukan tepat jam 15.00, pembakaran kayu dan batu untuk sep sudah dilakukan sejak pagi hingga siang hari, sekitar jam 13.00 bahan-bahan sep sudah dapat diatur diatas batu-batu yang telah panas lalu selanjutnya tutup dengan kulit kayu bus. Saat hampir jam tiga sore kulit kayu bus dibuka, wanita dan anak-anak keluar dari kebun. Kemudian beberapa kepala keluarga atau kaum pria membuat dua atau tiga lubang tanam di setiap petak lahan dengan ditancap kayu pendek pada setiap lubang tanam.

Tepat jam lima sore pemimpin mengucapkan doa memohon kepada Dema agar tanaman dapat memberi hasil banyak dan dijauhkan dari hama dan penyakit sambil mengikatkan daun alang-alang pada setiap kayu pendek, sementara kaum pria lainnya membantu menanam kumbili. Pada jaman dahulu penanaman menggunakan tugal (ngkiep), namun saat ini pembuatan lubang tanam menggunakan cangkul atau sekop.

Selanjutnya dari setiap bahan makanan yang ada diambil sedikit demi sedikit dan diletakkan dibawah kayu misar, dimana menurut kepercayaan masyarakat Suku Kanum dengan telah diucapkan doa maka Dema datang dan tinggal di kayu misar tersebut, sehingga makanan tersebut adalah untuk makan Dema. Setelah kegiatan ritual yaitu doa dan penanaman kumbili selesai kaum wanita dan anak-anak kembali memasuki kebun. Kemudian bahan makanan lain dimakan bersama, jika masih ada sisa bahan makanan maka dibagi rata untuk keluarga yang datang membantu.

Setelah makan bersama, lahan ditinggalkan selama tiga hari, keluarga kembali ke kampung untuk istirahat. Menurut kepercayaan Suku Kanum ketika selama tiga 
hari kebun ditinggalkan maka Dema yang bekerja memberi kesuburan dalam kebun sehingga hasil panen banyak. Setelah tiga hari, keluarga kembali ke dusun dan mulai melakukan penanaman kumbili di petak masing-masing.

Untuk petak bagian anak-anak maka bapak dan ibunya yang menaruh kumbili di atas tanah tempat tanam, anak-anak yang membuat kuming dan menanam kumbili. Jarak antar tanaman kumbili adalah satu langkah kaki orang dewasa atau sekitar 50 $\mathrm{cm}$ dengan sistem segitiga. Cara tanam kumbili adalah membuat lubang tanam, gemburkan tanah, letakkan umbi posisi mendatar atau agak miring kemudian tutup dengan tanah. Secara ringkas, nilai budaya yang terkait dengan penanaman, disajikan pada Tabel-2 berikut.

Tabel-2.

Nilai Budaya terkait dengan Penanaman

\begin{tabular}{|c|c|c|c|}
\hline No & Jenis Kegiatan & Nilai budaya & Makna \\
\hline 1 & Persiapan benih & - Kebersamaan & $\begin{array}{ll}\text { - } & \text { Dilakukan bersama oleh keluarga } \\
\text { - } & \text { Mengajarkan anak-anak sedari kecil } \\
\text { - } & \text { tentang persiapan benih tanaman } \\
\end{array}$ \\
\hline \multirow[t]{3}{*}{2} & \multirow[t]{3}{*}{ Penanaman } & - Religi & $\begin{array}{l}\text { - Mohon ijin kepada Dema untuk } \\
\text { menanam di dusun dan memohon } \\
\text { Dema memberi kesuburan pada } \\
\text { tanaman dan menjauhkan kerusakan } \\
\text { oleh serangan hama penyakit } \\
\text { tanaman ataupun gangguan yang } \\
\text { lain. }\end{array}$ \\
\hline & & -Gotong royong & $\begin{array}{l}\text { - Kegiatan penanaman dibantu oleh } \\
\text { keluarga lain dan tetangga, saling } \\
\text { tolong menolong }\end{array}$ \\
\hline & & -Kebersamaan & $\begin{array}{l}\text { - Dilakukan secara bersama-sama } \\
\text { dengan pembagian tugas oleh kepala } \\
\text { keluarga pemilik kebun. }\end{array}$ \\
\hline
\end{tabular}

Sumber : Data primer 2018

\section{Pemeliharaan Tanaman.}

Kegiatan ini meliputi pemupukan dan pemasangan tajar kedua. Empat bulan setelah tanam biasanya pada bulan Januari atau ketika masyarakat melihat rebung tanaman bambu sudah tumbuh adalah waktu pembumbunan dan cabut duri. Bersamaan dengan cabut duri biasanya dilakukan penjarangan umbi yaitu membuang umbi ukuran kecil dan mengatur letak umbi agar memperoleh ruang yang cukup sehingga dapat menjadi umbi dengan ukuran besar, lalu kegiatan pembumbunan. Kegiatan pencegahan hama dan penyakit yang biasa dilakukan oleh masyarakat Suku Kanum cukup sederhana yaitu dengan menaruh abu dapur di sekitar perakaran tanaman kumbili. Bila terlihat daun tanaman kumbili sudah menguning sebelum waktunya masyarakat mengambil sejenis siput rawa yang panjang lalu tanam dekat tanaman kumbili maka daunnya akan kembali menghijau. Ada pula beberapa anggota keluarga yang secara berkala menyemburkan kencur yang dikunyah disekeliling lahan. 
Jurnal Sosial Ekonomi Pertanian p-ISSN 0853-8395, e-ISSN 2598-5922 


\section{Panen.}

Masyarakat Suku Kanum mulai memanen kumbili sejak akhir Bulan Mei dengan cara membongkar bumbunan mengambil umbi yang ukuran besar saja sesuai kebutuhan keluarga. Panen secara keseluruhan dapat dilakukan bila daun sudah menguning dan mengering yaitu sekitar bulan Juli atau Agustus. Sehari sebelum panen keluarga menyiapkan ritual adat seperti pada kegiatan pembersihan lahan berupa pembuatan sep. Pemanenan secara bertahap yaitu mulai dari petak lahan milik kepala keluarga/bapak, selanjutnya anak laki-laki, petak milik ibu lalu anak perempuan.

Kegiatan panen diawali dengan rapat bersama beberapa anggota keluarga menentukan waktu panen yang tepat dengan mempertimbangkan persiapan keluarga yaitu mempersiapkan bahan makanan dan peralatan yang diperlukan, membersihkan gudang penyimpanan kumbili, memperbaiki bevak serta mengundang keluarga lain yang akan membantu.

Sehari sebelum panen keluarga menyiapkan ritual adat seperti pada kegiatan pembersihan lahan berupa pembuatan sep di sisi lahan yang akan digunakan untuk menumpuk hasil panen sementara. Tepat jam 15.00 kepala keluarga yang ditunjuk memimpin doa kepada Dema mengucapkan terimakasih karena akan panen sambil mencungkil satu kuming kumbili. Keesokan harinya baru panen bersama. Pada jaman dahulu ritual adat ini harus dilakukan namun saat sekarang tidak selalu dilakukan. Saat ini hanya mengucapkan doa pada jam 15.00 dan memanen 1 kuming saja. Pemanenan secara bertahap yaitu mulai dari petak lahan milik kepala keluarga/bapak, selanjutnya anak laki-laki, petak milik ibu lalu anak perempuan.

\section{Kesimpulan}

Pengelolaan sistem usahatani pola dusun masyarakat Suku Kanum diiringi dengan kegiatan ritual adat sejak persiapan lahan sampai kegiatan panen. Beberapa nilai budaya yang terkandung dalam kegiatan ritual adat antara adalah: (1) Nilai keselamatan, berdoa untuk keselamatan bersama (mereka percaya bahwa kehidupan mereka ada yang mengendalikan secara spiritual sehingga dengan berdoa bersama mereka percaya akan diberikan keselamatan dalam mengelola lahan); (2) Nilai religi, memohon izin kepada Dema (mereka percaya bahwa semua lahan yang akan dikelola ada pemilik atau penjaganya); dan (3) nilai kebersamaan (kegiatan dilakukan secara bersama oleh anggota rumah tangga) dan kegotongroyongan (kegiatan dilakukan secara bersama oleh warga) dan nilai tanggung jawab, dilakukan dalam bentuk melibatkan dan mengajarkan anak-anak sedari kecil untuk melakukan budidaya kumbili (mereka percaya dengan pembagian petak lahan yang sedini mungkin maka semakin memicu munculnya rasa tanggungjawab masyarakat Suku Kanum dalam mengelola kegiatan usahatani pola dusun yang merupakan haknya).

\section{Daftar Pustaka}

Ali, M. S.S. and Rahmadanih. 2017. Ecological Wisdom in Slash Burning Farming of Remote Indigenous Community in North Mamuju Regency. International Journal of Agriculture System. Vol 5 (2). http://pasca.unhas.ac.id/ ojs/index.php/ijas/article/view1256 
Badan Pusat Statistik, 2017. Merauke Dalam Angka Tahun 2017. Kantor Statistik Merauke, Papua.

Balai Taman Nasional Wasur (BTNW), 1999. Rencana Pengelolaan Taman Nasional Wasur 1999 - 2024. Buku I.

Darwin, B., L.O.M, Tawolu, M.A. 2016. Implementasi Nilai-nilai Sosial Budaya Pokadulu. 2016.

http://ojs.uho.ac.id/index.php/NeoSocietal/article/view/3395. Diakses tanggal 26 Juni 2018.

La Nalefo, J. Jusoff, M.S.S. Ali, D. Salman, E.B., Demmallino, Meisanti, Muhidin, I.Y. Ismail, M. Kamaluddin, Nurwati, 2013. Towards on Institutional Sustainable Agriculture in Parabela, World Applied Science Journal, Vol.26:55-59.

Meisanti, K. Jusoff, D. Salman, D. Rukmana, 2012. “The Impacts of Gold Mining on the Farmers Community". American Journal of Sustainable Agriculture, 6: 209-214.

Mulyadi , I.D.A, 2016. Pengaruh Nilai Budaya Lokal Terhadap Motivasi Bertani Suku Arfak di Papua Barat. Journal Peternakan Sriwijaya. Vol. 5, No, I. Hal. 21. https:/ / anzdoc.com/pengaruh-nilai-budaya-lokal-terhadap-motivasibertani-suku-a.html. Diakses tanggal 26 Juni 2018.

Purwanto Y. dan A. Cosiaux, 2010. Studi Sistem Pertanian Tradisional Masyarakat Negeri Saleman, Seram Utara, Kabupaten Maluku Tengah. Laporan Penelitian COLUPSIA Project, CIRAD dan UNIEROPA.

Ruky, A.S, 2017. Budaya, Kebudayaan dan Nilai-nilai Budaya. https:/ / achmadruky.com/321/budaya-kebudayaan-dan-nilai-nilai-budaya. Diakses tanggal 26 Juni 2018.

Saputra, G.P, 2011. Nilai Budaya, Sistem Nilai dan Orentasi Nilai Budaya. http://wirasaputra.Wordpress.com. Diakses tanggal 5 Februari 2018

Silalahi, U, 2009. Metode Penelitian Sosial. Bandung: PT Refika Aditama

Sugiyono, 2015. Memahami Penelitian Kualitatif. Bandung: CV. Alfabeta.

Sugiyono, 2016. Metode Penelitian Kombinasi. Bandung: CV. Alfabeta

Yunus, A., D. Salman, EB. Demmallino, NM. Viantika, 2016. “Sosiotechnical Change and Institutional Adjustment in Paddy Rice Farming During Post Green Revolution in Indonesia". International Journal of Agriculture Science, 4 (2): 218227. 